\title{
Important to Emergency Medicine, Medical Intensive Care and Anesthesiology Trends in Hospital Admissions Due to Poisonings by Antiepileptic, Sedative-Hypnotic and Anti-Parkinsonism Drugs (T42 ICD-10) in the Lower Silesia Region of Poland in the Years 2006-2012
}

\author{
Jaroslaw Drobnik ${ }^{1}$, Grzegorz Odonicz-Czarnecki ${ }^{2}$, Robert Suslo ${ }^{1}$ \\ ${ }^{1}$ Public Health Department, Wroclaw University Hospital, 213 Borowska St, 50-556 Wroclaw, Poland \\ ${ }^{2}$ Orthopedics and Musculoskeletal Traumatology Clinics, Wroclaw, 213 Borowska St, Wroclaw, \\ Poland
}

\begin{abstract}
Acute poisonings with sedative-hypnotic drugs often constitute a serious challenge for emergency medicine and medical intensive care specialists as well as for anesthesiologists, as they comparably often cause acute central respiratory insufficiency suppressing the respiratory drive. Data on causes of hospital admissions because of poisoning by antiepileptic, sedative-hypnotic and antiparkinsonism drugs (T42 according to ICD-10) in the years 2006-2012, made available due to courtesy of the public healthcare insurance provider Narodowy Fundusz Zdrowia in Lower Silesia region of Poland (NFZ), were analyzed to find out the current incidence and trends in the most common and important intoxications. The amount of diagnosed intoxications with hydantoin derivatives, anti-parkinsonism drugs and other central muscle-tone depressants remained unchanged in the analyzed period of time, while the amount of admissions due to poisonings by iminostilbenes, succinimides, oxazolidinediones and anti-epileptics needing hospital admission dropped significantly. The revealed decline in hospital admissions due to poisonings by barbiturates and benzodiazepines indicates that in the Lower Silesia region of Poland physicians limited the scale of prescribing those potentially dangerous and dependency causing drugs. The slight increase in the amount of reported poisonings by not further specified antiepileptic, sedative-hypnotic and anti-parkinsonism drugs and the presence of reported poisonings by unspecified drugs from these groups suggests insufficient toxicological tests availability and the need for introducing into the standard different tests detecting broader spectrum of substances.
\end{abstract}

Keywords: sedatives; hypnotics; antiepileptics; toxicology; public health; forensic medicine; drug abuse statistics

Abbreviations: NFZ - Narodowy Fundusz Zdrowia in Lower Silesia region of Poland, District Division in Wroclaw

\section{INTRODUCTION}

Acute poisonings with sedative-hypnotic drugs often constitute a serious challenge for emergency medicine and medical intensive care specialists as well as for anesthesiologists, as they comparably often cause acute central respiratory insufficiency suppressing the respiratory drive. Even a full autopsy does not reveal the cause of death in such cases if its results are not supported with proper toxicology testing - as it unfortunately is not applied routinely in each case of forensic autopsy in Poland it allows diagnosing routinely only mechanical causes of asphyxia [1]. Quite often drugdependent patients tend to literally coerce a physician, especially a family doctor, to prescribe them sedative-hypnotic medicaments in excessive amounts; sometimes the same patient visits several different physicians in the row to collect prescriptions for the drug they desire. Such as situation, if not properly managed, shall make the physician seriously consider ending the faulty relationship with the patient and transferring him/her to some other colleague's practice [2]. Often an acute poisoning with medical drugs is a manifestation of long lasting medicinal drugs abuse. As soon as such condition is diagnosed it shall be immediately documented in medical files, especially as it may alter the metabolism of many drugs applied routinely at different medical occasions, sometimes leading to unexpected effects of otherwise properly administered drug [3]. The proper doses of drugs may exercise paradoxically strong effects in individuals with rare genetic metabolism or receptors disorders [4]. Sometimes the accidental intoxications arise from impaired physician- 
patient communication or even from a plain information medical mistake - resulting in overdose [5]. Such a possibility must be taken into account especially in case of mentally incapacitated or senile patients [6]. Intoxication with sedative-hypnotic drugs shall be always taken into account in unclear cases of suspected or reported suicide, sexual abuse [7], and workplace or traffic accidents [8]. The sedative-hypnotic drugs shall be prescribed cautiously and the fact of the prescription shall be scrupulously documented by the physician in the medical files [9], along with proper remarks on the passed by the physician to the patient information on drug's side effects and limitations in the use of mechanical devices [10]. There are cases in which respiratory drive depressants side effects manifestation happens in hospital when they are administered in excessive amounts by medical staff with the intention to "calm down" a patient who in their opinion is "without any reason" sleepless, scarred, irritated, over-reactive or hyperactive - while in reality the patient is just at the very moment developing some serious pathologic, somatic or psychiatric, condition [11]. The risk of serious respiratory drive depression shall be not associated - as it commonly is in case of many physicians - merely with sedative-hypnotic drugs and opiates therapy; overdose of muscle relaxants also can cause potentially deadly intoxications needing immediate toxicological evaluation and assistance of emergency medicine, intensive care physicians as well as anesthesiologists [12].

\section{MATERIALS AND METHODS}

Data on causes of hospital admissions because of poisoning by antiepileptic, sedative-hypnotic and antiparkinsonism drugs (T42 according to ICD-10) in the years 2006-2012, made available due to courtesy of the public healthcare insurance provider Narodowy Fundusz Zdrowia in Lower Silesia region of Poland (NFZ), were analyzed. The aim of the study was to find out the current incidence and trends in the most common and important intoxications in the analyzed period of time to facilitate the process of toxicology diagnostics for both clinical and forensic medicine purposes.

\section{RESULTS AND DISCUSSION}

In the years 2006-2012 the amount and age structure of the Lower Silesia region of Poland population did not change significantly although there were signs of population ageing [13]. In the year 2014 in the Lower Silesia there were living 2,9 million people,52\% of them females [14].

The yearly amount of admissions to hospitals of the Lower Silesia region in the years 2006-2012 that were reported as caused by poisoning by antiepileptic, sedative-hypnotic and anti-parkinsonism drugs without any further specification (T42 according to ICD-10) was alternating, but the general trend was increasing, as it is shown in Figure 1.

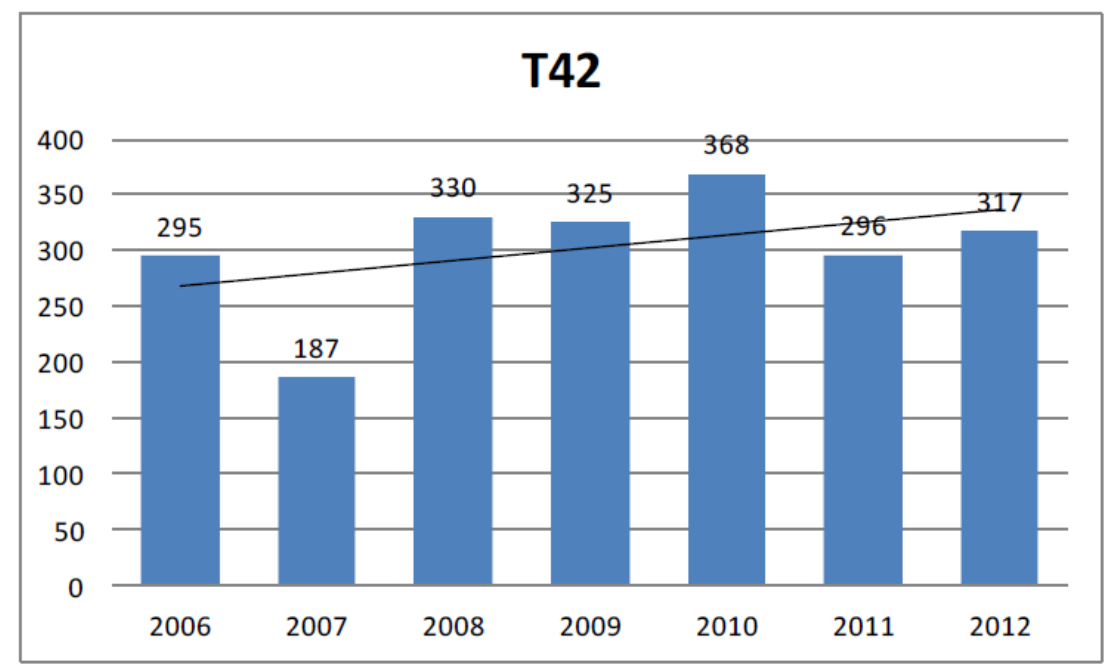

Figure1. Yearly amounts of admissions to hospitals in the Lower Silesia region of Poland in the years 20062012 reported as being due to poisoning by antiepileptic, sedative-hypnotic and anti-parkinsonism drugs (T42 according to ICD-10) not specified further; source: data made available by courtesy of the NFZ

Poisonings by hydantoin derivatives (T42.0 according to ICD-10) were alternating from year to year, but there was no distinctive trend in the changes that would be visible in the analyzed period, as it is shown in Figure 2. 
Important to Emergency Medicine, Medical Intensive Care and Anesthesiology Trends in Hospital Admissions Due to Poisonings by Antiepileptic, Sedative-Hypnotic and Anti-Parkinsonism Drugs (T42 ICD-10) in the Lower Silesia Region of Poland in the Years 2006-2012

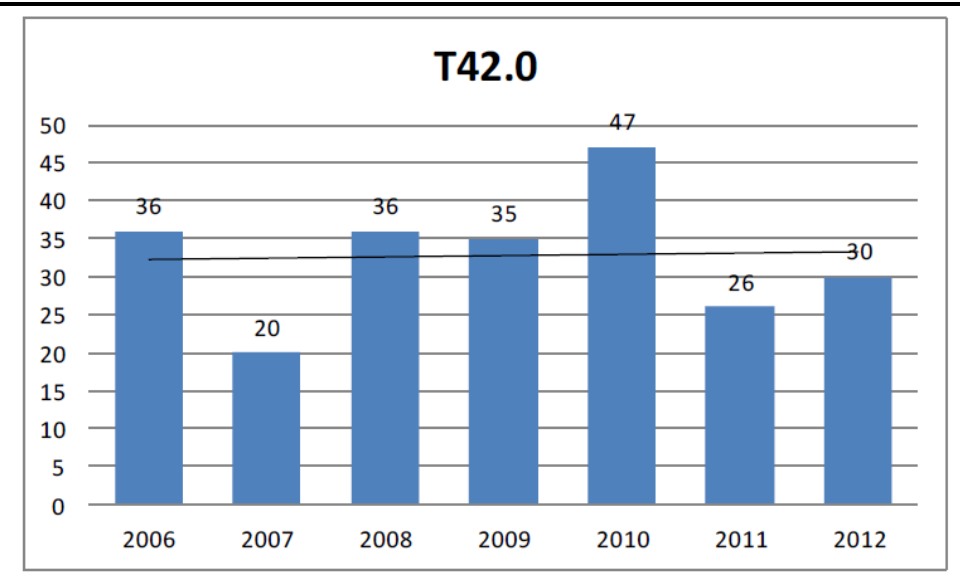

Figure2. Yearly amounts of admissions to hospitals in the Lower Silesia region of Poland in the years 20062012 due to poisoning by hydantoin derivatives (T42.0 according to ICD-10); source: data made available by courtesy of the NFZ

The yearly amount of hospital admissions caused by poisonings by iminostilbenes (T42.1 according to ICD-10) dropped significantly in the analyzed period -to $44,1 \%$ of its initial value, as it is demonstrated in Figure 3.

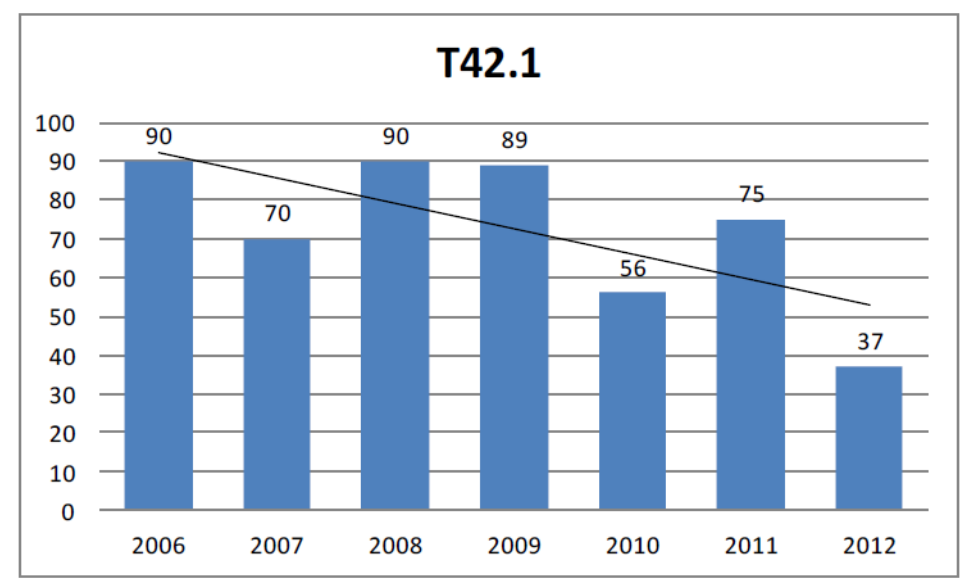

Figure3. Yearly amounts of admissions to hospitals in the Lower Silesia region of Poland in the years 20062012 due to poisoning by iminostilbenes (T42.1 according to ICD-10); source: data made available by courtesy of the NFZ

Even more pronounced decreasing trend was observed in the amount of admissions to Lower Silesia region of Poland hospitals due to poisonings by succinimides and oxazolidinediones (T42.2 according to ICD-10) - to $16,1 \%$ of its initial value, as it is shown in Figure 4.

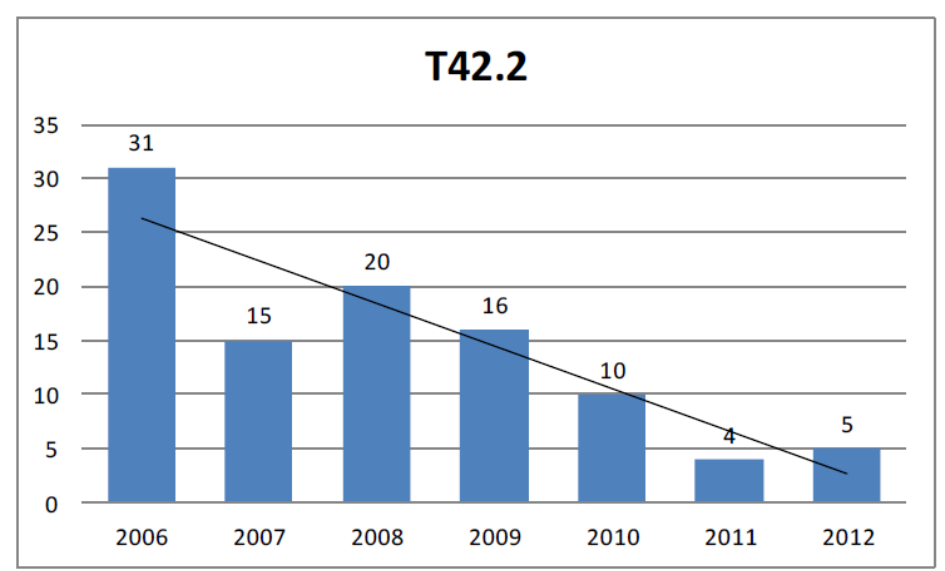

Figure4. Yearly amounts of admissions to hospitals in the Lower Silesia region of Poland in the years 20062012 due to poisoning by succinimides and oxazolidinediones (T42.2 according to ICD-10); source: data made available by courtesy of the NFZ 
A significant fall was also registered in hospital admission caused by poisonings by barbiturates (T42.3 according to ICD-10) - to $35,3 \%$ of its initial value, as it is visualized in Figure 5.

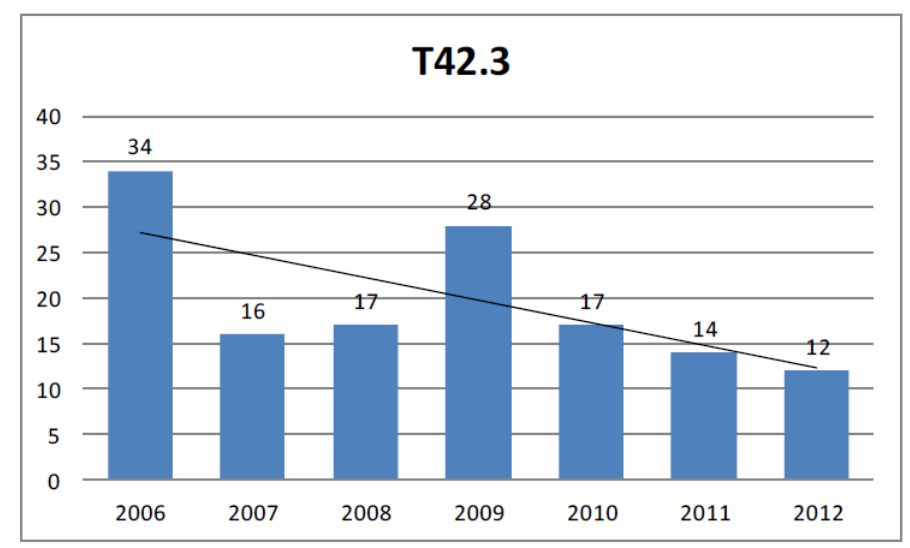

Figure5. Yearly amounts of admissions to hospitals in the Lower Silesia region of Poland in the years 20062012 due to poisoning by barbiturates (T42.3 according to ICD-10); source: data made available by courtesy of the NFZ

The yearly amounts of reported hospitalizations due to poisonings by benzodiazepines (T42.4 according to ICD-10) were alternating in the years 2006-2012 in the Lower Silesia region of Poland, but a general decreasing trend was visible. In the end of the analyzed period the amount of hospital admissions dropped to 78,2\% of its initial value, as it is demonstrated in Figure 6.

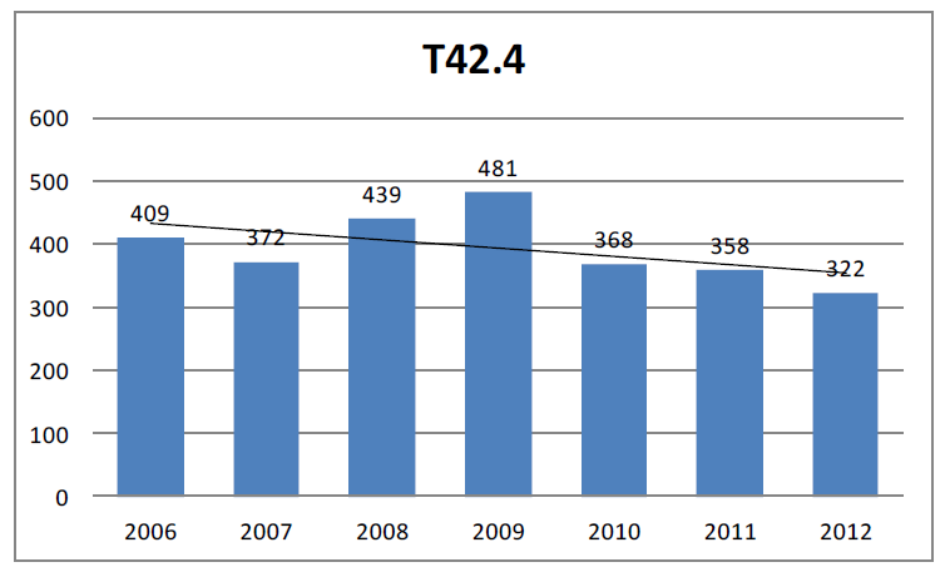

Figure6. Yearly amounts of admissions to hospitals in the Lower Silesia region of Poland in the years 20062012 due to poisoning by benzodiazepines (T42.4 according to ICD-10); source: data made available by courtesy of the NFZ

A significant diminishing of the amount of hospital admissions because of poisonings by mixed antiepileptics (T42.5 according to ICD-10) dropped rapidly in the beginning of the analyzed time period and then stayed low, a the level of $36,4 \%$ of its initial value, as it is shown in Figure 7.

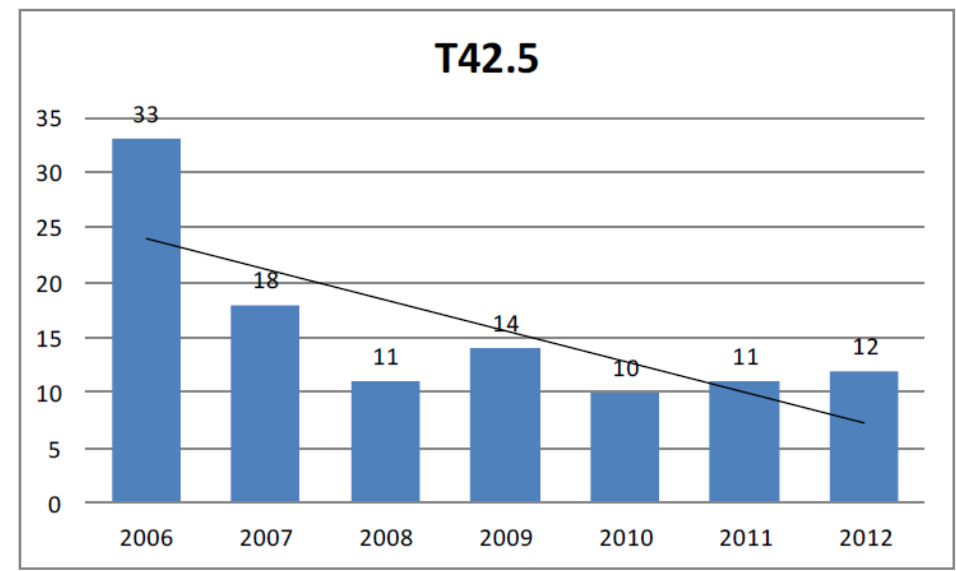

Figure7. Yearly amounts of admissions to hospitals in the Lower Silesia region of Poland in the years 20062012 due to poisoning by mixed anti-epileptics not classified elsewhere (T42.5 according to ICD-10); source: data made available by courtesy of the NFZ 
Important to Emergency Medicine, Medical Intensive Care and Anesthesiology Trends in Hospital Admissions Due to Poisonings by Antiepileptic, Sedative-Hypnotic and Anti-Parkinsonism Drugs (T42 ICD-10) in the Lower Silesia Region of Poland in the Years 2006-2012

Poisonings by anti-epileptics and sedative-hypnotic drugs that are not included in the categories T42.0-T42.5 (T42.6 according to ICD-10) showed the raising trend and increased by $28,0 \%$ of its initial value, as it is demonstrated in Figure 8.

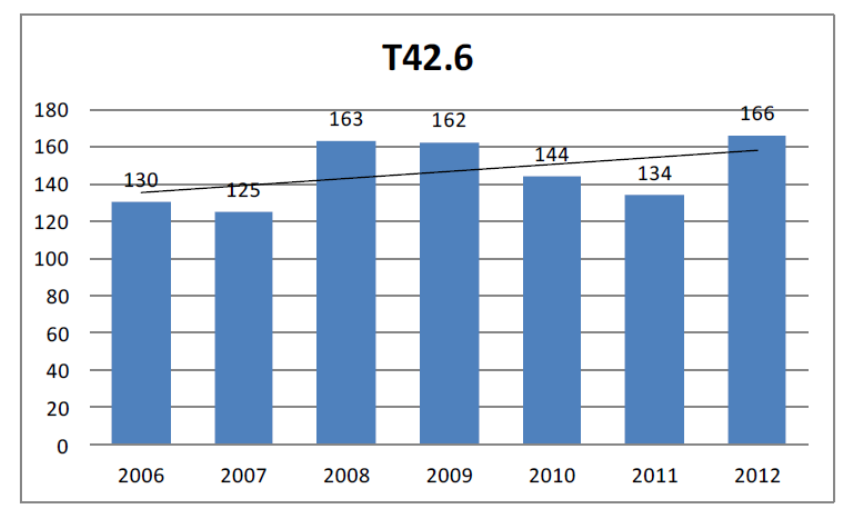

Figure8. Yearly amounts of admissions to hospitals in the Lower Silesia region of Poland in the years 20062012 due to poisoning by other than T42.0-T42.6 anti-epileptics and sedative-hypnotic drugs (T42.6 according to ICD-10); source: data made available by courtesy of the NFZ

The yearly amounts of admissions to hospitals of the Lower Silesia region due to poisonings by unspecified anti-epileptic and sedative-hypnotic drugs (T42.7 according to ICD-10) were alternating during the analyzed time period without showing any strongly distinguishable change trend and in its end dropped to $81,5 \%$ of the initial value, as it is demonstrated in Figure 9.

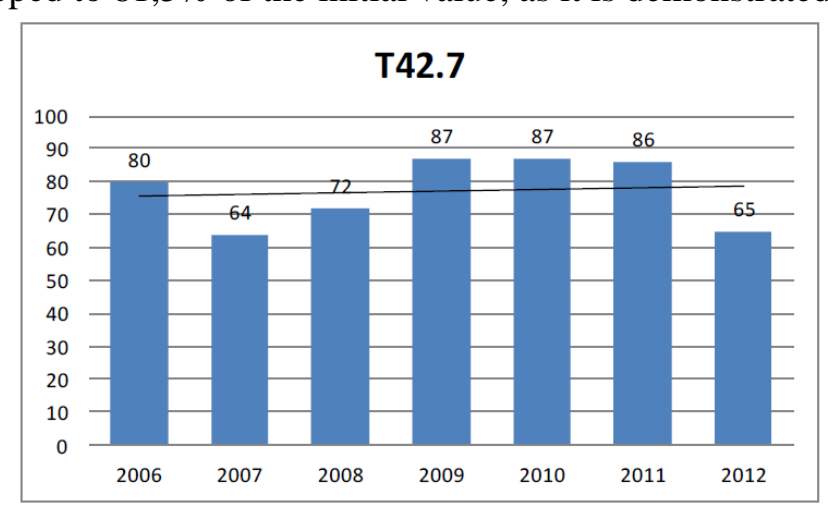

Figure9. Yearly amounts of admissions to hospitals in the Lower Silesia region of Poland in the years 20062012 due to poisoning by unspecified anti-epileptic and sedative-hypnotic drugs (T42.7 according to ICD-10); source: data made available by courtesy of the NFZ

The amounts of cases of poisonings by anti-parkinsonism drugs and other central muscle-tone depressants (T42.8 according to ICD-10) among the patients admitted to hospitals in the Lower Silesia region of Poland were alternating in the years 2006-2012 and no strongly pronounced trend was visible in the changes, as it is shown in Figure 10.

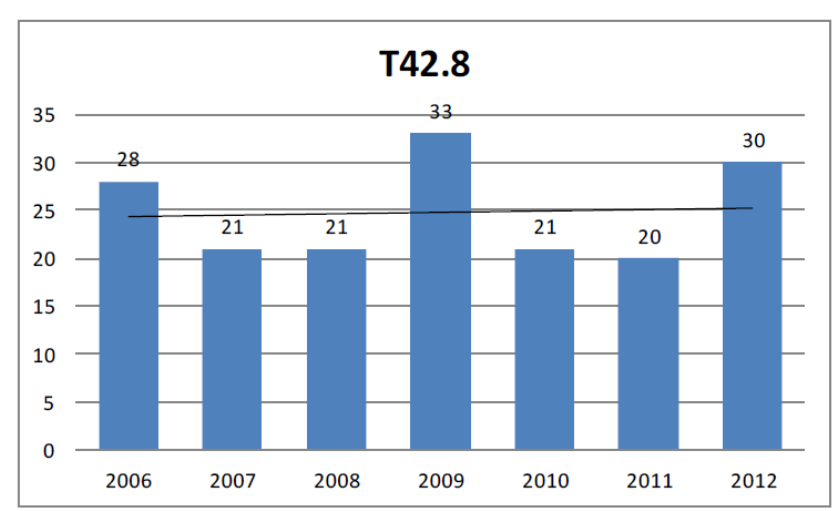

Figure10. Yearly amounts of admissions to hospitals in the Lower Silesia region of Poland in the years 20062012 due to poisoning by anti-parkinsonism drugs and other central muscle-tone depressants (T42.8 according to ICD-10); source: data made available by courtesy of the NFZ 


\section{CONCluSiON}

Emergency medicine, intensive care and anesthesiology specialists taking care of victims of poisonings by antiepileptic, sedative-hypnotic and anti-parkinsonism drugs in the Lower Silesia region of Poland in the years 2006-2012 the amount of hospitalizations because of was stabile, with some positive trends.

The amount of diagnosed intoxications with hydantoin derivatives, anti-parkinsonism drugs and other central muscle-tone depressants remained unchanged in the analyzed period of time, while the amount of admissions due to poisonings by iminostilbenes, succinimides, oxazolidinediones and antiepileptics needing hospital admission dropped significantly.

Especially optimistic is the decline in hospital admissions due to poisonings by barbiturates and benzodiazepines - it indicates that in the Lower Silesia region of Poland physicians limited in the analyzed time period the scale of prescribing those drugs that have the proven high dependency build up potential and are often used in suicide attempts.

The slight increase in the amount of reported poisonings by not further specified antiepileptic, sedative-hypnotic and anti-parkinsonism drugs and the presence of reported poisonings by unspecified drugs from these groups suggests that there is room for improvement of the toxicological laboratories availability in the Lower Silesia region of Poland. Together with the increase of reported cases of intoxications with untypical anti-epileptics and sedative-hypnotic drugs it indicates also that the emergency medicine and intensive care specialists as well as anesthesiologists could benefit from introduction of more sophisticated analytical methods into screening tests performed by hospital toxicology laboratories that posses the capability of diagnosing broader spectrum of substances.

\section{ACKNOWLEDGMENTS}

The authors thank the NFZ for allowing them the access to the publication-relevant data.

\section{REFERENCES}

[1] Trnka J, Gesicki M, Suslo R, Siuta J, Drobnik J, Pirogowicz I.: Death as a result of violent asphyxia in autopsy reports; Adv.Exp.Med.Biol. 2013 Vol.788: Neurobiology of respiration; PP 413-416

[2] Suslo R, Trnka J, Drobnik D.: Refusal of treatment in the case of family doctor; Fam.Med.Prim.Care Rev. 2008 Vol.10 no.3; PP 1086-1090

[3] Suslo R, Drobnik J, Trnka J.: Rozpoznawanie i dokumentowanie przypadkow przewleklej intoksykacji wsrod pacjentow podstawowej opieki zdrowotnej; Przew.Lek. 2010 nr 2; PP 180183

[4] Suslo R, Trnka J, Siewiera J, Drobnik J.: Ondine's curse - genetic and iatrogenic central hypoventilation as diagnostic options in forensic medicine; Adv.Exp.Med.Biol. 2015 Vol.861: Neuroscience and respiration. Vol.14: Respiratory health; s.65-73

[5] Drobnik J, Trnka J, Suslo R, Steciwko A.: The new category of the medical error - the inquiry error; Fam.Med.Prim.Care Rev. 2009 Vol.11 no.3; PP 593-594

[6] Suslo R, Siuta J, Trnka J, Gesicki M, Drobnik J.: Sadowo-lekarskie problemy przy okreslaniu przyczyny zgonu w przypadku osob starszych, ktore zmarły w niejasnych okolicznosciach; Acta Univ.Lodz., Folia Oecon. 2013 No 297: Pomyslne starzenie sie - uwarunkowania spoleczne, przestrzenne i zdrowotne; PP 225-236

[7] Trnka J, Drobnik J, Suslo R.: Badania i sporzadzanie dokumentacji medycznej w przypadku ofiar przestepstw na tle seksualnym; Przew.Lek. 2009 nr 1; PP 257-261

[8] Suslo R, Trnka J, Drobnik J.: The use of medical documents for the purposes of opinion giving in traffic accidents cases; Fam.Med.Prim.Care Rev. 2009 Vol.11 No.3; PP 767-772

[9] Trnka J, Suslo R, Drobnik J, Mastalerz-Migas A.: Rules of handling medical recipes; Fam.Med.Prim.Care Rev. 2008 Vol.10 No.3; PP 1122-1125

[10] Drobnik J, Suslo R, Trnka J, Kordel K.: The importance of the proper provision of information to patients about medicines in the context of the risks in road traffic and workplace; Fam.Med.Prim.Care Rev. 2011 Vol.13 No.2; PP 302-304 
Important to Emergency Medicine, Medical Intensive Care and Anesthesiology Trends in Hospital Admissions Due to Poisonings by Antiepileptic, Sedative-Hypnotic and Anti-Parkinsonism Drugs (T42 ICD-10) in the Lower Silesia Region of Poland in the Years 2006-2012

[11] Suslo R, Trnka J, Siewiera J, Drobnik J.: Hypoxia-related brain dysfunction in forensic medicine; Adv.Exp.Med.Biol. 2015 Vol.837: Neuroscience and respiration. Vol.6: Neurotransmitter interactions and cognitive function; PP 49-56

[12] Szpot P, Chlopas A, Buszewicz G, Teresinski G.: Application of high-resolution mass spectrometry to determination of baclofen in a case of fatal intoxication; Forensic Toxicol. [online] 2016 PP 1-9, pos 41, [accessed: 25.05.2016]. DOI: 10.1007/s11419-016-0314-0.

[13] Drobnik J, Suslo R, Kurpas D, Trnka J.: Analysis of elderly people care system and their health needs in the Lower Silesia region; Fam.Med.Prim.Care Rev. 2010 Vol.12 no.2; PP 165-167

[14] Central Statistical Office of Poland Information Portal http://stat.gov.pl/statystykaregionalna/rankingi-statystyczne/ludnosc-wedlug-wojewodztw/ [accessed: 22.05.2016] 